\title{
Nanoremediation- Clean up technology for water pollution
}

\author{
Vibha Gupta \\ Department of Botany, G.N.Khalsa College, Matunga 19.
}

\begin{abstract}
The most challenging task of the recent time is to search for ecofriendly, sustainable and economically feasible technology for cleaning water resources. Nanotechnology is one of the emerging technology of the current time which offers several environmental applications including remediation of water pollution. It is a promising clean up technology to combat water pollution wherein various methods can be involved to form new products, improve existing instruments and helps in reformulating new materials and chemicals which has better performance. It is therefore referred as green technology in terms of energy conservation and reduces the release of toxic compounds into environment. Nanotechnology in future holds great promises in remediating water related pollution problems in a sustainable way. The following review article summarizes the recent trends in the ongoing research related to environment remediation by nanotechnology.
\end{abstract}

Keywords:

Nanotechnology, remediation, water pollution, environmental applications, sustainable

Article Received: 18 October 2020, Revised: 3 November 2020, Accepted: 24 December 2020

\section{Introduction:}

Water contaminated from various resources such as industrial effluents, agricultural and farm practices, lab wastes, residential places etc. with organic and inorganic pollutants is the most important concern of the recent time $[1,2]$. The treatment measures can reduce these concerns [3] but traditional methods used for the water treatment are not enough to completely remove the emerging contaminants and meet stringent water quality standards [4]. It is reported that several drawbacks are associated with existing technologies in terms of high energy consumption, incomplete pollutant removal, toxic sludge generation etc. [3].

One of the major developments in the water remediating process is bioremediation in which various biological agents such as bacteria, fungi and enzymes are used to degrade contaminants to less harmless forms [5]. It has additional advantages of competence, metal selection, metal recovery over conventional approaches. Bioventing, bioleaching, bioaugumentation [6] are some of the techniques involved in bioremediation. It offers a sustainable solution for the treatment of contaminated waters but bio- based approaches are time consuming, becomes toxic at high concentration to the organism involved [7, 8, 9]. A comprehensive review was presented about the common methods used in the treatment along with their advantages and disadvantages [10].

In the above context, there is real requirement for powerful and efficient treatment of wastewaters [11]. Among the various technologies, Nanoremediation adds a new dimension to solve the problems associated with water pollution [12, 13].

\section{Nanotechnology- Treatment of water bodies}

Contamination of various water bodies including groundwater from industries is a matter of great concern. The affected areas such as lakes, rivers in their vicinity, underground storage tank leakages, landfills etc. shows the presence of heavy metals [14] such as pollutants (eg: mercury, lead, cadmium,) and organic compounds (eg: benzene, chlorinated solvents, creosote). Currently conventional methods which are employed to remove toxic contaminants are laborious, time consuming and expensive techniques. Also during removal of these contaminants from affected areas, ecosystem can also be disturbed. 
Nanotechnology offers high tech applied science that can perform in situ remediation and reach inaccessible areas such as crevices and aquifers and eliminates the use of costly pumps and treatment operations [15, 16, 17]. Working at nanoscale can be used to develop remediation tools that are specific for certain pollutants (eg: metal), enhances affinity and selectivity as well as improving the sensitivity of the technique [18, 19]. Another aspect includes drinking water and its contamination from pollutants. Two toxic metals that possess very high health risks are mercury and arsenic. Again nanoscience offers high throughput solutions with new methods for the purification, waste water management and desalinization of water [20].

\subsection{Preference of Nanoremediation technology:}

Nanoremediation has introduced a new dimension to science and technology sector due to its properties at nanodimensions. The technology focuses on synthesis, design, characterization and application of nanomaterials and nanodevices. It involves the study of phenomenon and manipulation of materials at nanoscale [21, 22] which exhibits significant changes in physical, chemical, and biological properties due to their size, structure, surface ratio etc. over bulk materials, opening new avenue in material sciences [23]. These properties allows developing highly miniature, accurate and sensitive pollution monitoring devices called nanosensors. Thus with challenging issues due to complexicity of the mixture of different compounds with low reactivity, recent studies have focused on the use of nanoscience based projects such as to monitor, recognize and treat the contaminants that are found in parts per million (ppm) in water bodies for the development of environmental remediation technologies [24]. It is reported that near about 70 sites around world have used nanoremediation techniques at pilot scale projects $[16,17,25]$. In this context nanotechnology offers many thrust areas to reduce and treat environmental contaminants in manipulating at atomic scale and molecular level helps in fabricating with specific properties that can recognize particular type of pollutants within a mixture.

\section{Iron nanoparticles : In situ treatment}

Use of nanotechnology in the treatment of contaminated groundwater is well shown by iron nanoparticles. Iron in presence of air oxidizes easily to rust but in presence of contaminants such as $\mathrm{CCl}_{4}$, dioxins, parachlorobenzenes, when iron oxidizes, these organic contaminants are broken down into simpler forms. The practice of using iron powders (being non toxic and abundant) to clean up was found to be less effective [24] as it partially treats the industrial wastes and produces toxic by- products. Nanosized iron powders are injected at contaminated sites and are transported effectively by the flow of ground water. The properties of these nanoparticles do not change by soil conditions such as acidity, temperature and nutrient levels. It thus results in complete transformation and detoxification of environmental contaminants without formation of any toxic by-products and reduces contaminant level. It is reported that the iron nanoparticles remain active in a site for 8 weeks (approximately) before they become dispersed completely in the ground water and become less concentrated [24]. Experimental results collected have shown that a nanoscale iron particle are very effective against chlorinated organic solvents, organochlorine pesticides as contaminants and brings about complete transformation and detoxification. Preliminary research is going on to use this technique for remediation of aquifers and for immobilization of heavy metals and radionucleotides. Bimetallic iron nanoparticles such as iron palladium [26] is also shown to be more active, which can further enhance the improvement in remediation technology by anchoring these on solid support such as activated carbon or silica.

Iron at nanoscale is synthesized from Fe (II) and Fe (III) using borohydride as reductant. They 
possess a typical core shell structure consisting of primarily zero valent or metallic iron. Zero valent iron is a preferred choice due to large surface area, more reactive sites, dual properties of adsorption and reduction, enables to be used for remediation of wide range of contaminants present in situ [14, 20]. It also release less amount of toxic wastes during treatment process and can be modified based on contaminants [27] such as coatings of polyelectrolyte [28], encased in emulsified vegetable oil [29]. Nanoscale iron particles showed that they are highly effective for transformation and detoxification of large number of pollutants especially chlorinated organic solvents, organochlorine pesticides and polychlorinated biphenyls (PCBs) [30].

Although use of iron nanoparticles for in situ water remediation technology is beneficial and can replace traditional practices, its potential risks are poorly understood. The factors and processes affecting ecotoxicity are complex and knowledge of its potential impacts on human health is still limited.

\section{Solar photocatalysis remediation:}

A preliminary investigation for use of light in activating nanoparticles for their capability of removing contaminant is also another area of application of nanotechnology. It was found that nanosized titanium oxide and zinc oxide which are activated by light are considered to remove water contaminants because of their easily availability, inexpensive and helps in conversion of toxic contaminants (chlorinated detergents) into non toxic products [31]. Thus photodegradation of numerous toxic compounds by these semiconductors is possible but requires an improvement in terms of efficiency as titanium oxide or zinc oxide absorb UV light. Herein nanotechnology can bring an improvement by modifying surfaces with organic and inorganic dyes so that these oxides will have improved photoresponse from UV to visible light [32]. Recently it was shown that $\mathrm{ZnO}$ nanoparticles can act as a sensor and photocatalytic degradation of chlorinated phenols [33]. Various range of parameters such as $\mathrm{TiO}_{2}$ loading, $\mathrm{pH}$, temperature, dissolved oxygen, contaminated type, concentration, light intensity has to be standardized before their use in water quality improving [34].

Testing at pilot scale of commercial product Purifics Phot-Cat_system proves highly efficient for removing organics without producing waste streams and operation at low power [35, 36]. Solar disinfection based on nano $\mathrm{TiO}_{2}$ has been extensively tested and appears to be feasible option to produce safe drinking water in remote areas of developing countries. Its large scale industrial applications still possess several technical challenges such as catalyst optimization, efficient reactor design, reactor selectivity etc.

\section{Dendrimers :}

Dendrimers are polymers which are comprised of smaller molecules linked together. They are relatively monodipersed and highly branched macromolecules. Dendrimers-nanoparticle composites owing to have enhanced catalytic activity can be used in water treatment such as polyamidoamine dendrimers [37]. The researchers also developed simple filtration unit for removal of organic pollutants by utilizing $\mathrm{TiO}_{2}$ porous ceramic filters of which pores was impregnated with dendrimers offering high mechanical strength and high surface area [38]. These can be designed to act as cages and trap metal ions, making them soluble in media or able to bind to certain surfaces. In near future dendrimers holds place to be used as chelating agents for polymers supported as ultra-filtration.

6. Magnetic nanoparticles:

Magnetic property of rust nanoparticles can be used to remove arsenic from polluted water [39]. Arsenic pollutant sticks to rust which essentially is iron oxide (magnetic nature), thus this metal can be removed from water using magnet. Nano sized rust (10 $\mathrm{nm}$ in diameter) with high surface area, was found to improve removal of contaminants with high efficiency while reducing the amount of 
materials used [40, 41]. When compared to centrifugation or filtration systems, this technology has added advantage of not requiring electricity. This is very important especially in remote areas with limited or no access to electricity. Magnetic nanoparticles modified with specific functional groups are also used for the detection of microbes in water samples [20].

\section{Carbon nanotubes:}

Carbon nanotubes are known to have better absorbing efficiency when compared to activated charcoal [42, 43, 44, 45]. These nanotubes are rolled into single or multiwalled nanotubes, used as nanoadsorbents due to their ability to be attached to functional groups to increase the affinity towards target molecules [46], possess high chemical and thermal stability [47]. They are shown to remove heavy metals such as $\mathrm{Cr}^{3+}, \mathrm{Pb}^{2+}$, $\mathrm{Zn}^{2+}$, metalloids and organic impurities $[44,45$, 48]. Thus carbon nanotubes possess all properties which can maintain water of high quality. Reference [45] observed that multiwalled carbon nanotubes when oxidized with nitric acid showed high level of adsorption achieved. Absorption of $\mathrm{Pb}$ (II), $\mathrm{Cu}(\mathrm{II}), \mathrm{Cd}(\mathrm{II})$ on MCNTs were 3-4 times larger than powdered activated carbon and granular activated carbon which are conventionally used in water purification. CNTs are functionalized with functional groups such as hydroxyl, carboxyl, amines etc in order to be highly dispersed in water and biocompatibility in some cases $[49,50]$. It was also shown that FeMWCNT- $\mathrm{CH}_{2} \mathrm{COONa}$ can be used as potential sorbent to remove benzene and its aromatic compounds and can be reused owing to its magnetic property [51, 52].

9. Nanomembranes and nanofilters:

Nanotechnology is employed for the fabrication of nanofilters, nanoadsorbents, nanomembranes with specific properties used for decontaminating water.. Nanotraps are designed for certain contaminant having specific pore size and surface reactivity [27, 29]. Also membranes are engineered to trap and chemically react with contaminant and convert it to a non- toxic products. Reference [53] showed that these can help in removing micro size particles from aqueous phase with high elimination rate without fouling. Amplification of properties of membranes with reference to surface hydrophilicity, water permeability, fouling resistance is achieved by addition of metal oxide nanoparticles including alumina, silica, zeolite, titanium oxide [54, 55, 56]. This helps in inactivating microbes, reduces fouling by doping of polymeric membranes [57, 58, 59].

Researchers developed reverse osmosis membrane for sea water desalinization and waste water remediation [29]. Membrane made of cross linked matrix of polymers and engineered nanoparticles were designed to draw in water ions but repel contaminants. This is possible due to nanosize dimension of holes forming the membrane which are accessible only to water molecules and at same time they repel organic and microbes. These are thus less prone to clogging which increases the membrane lifetime with an economic benefit [30].

\section{Concerns:}

Numerous concerns arises with use of nanotechnology whether its nanoparticles or nanoengineered materials or devices. Their efficacy at polluted sites and their behavior in different types of environment raises serious concerns. Questions have been raised regarding its effects on various organisms and bioaccumulation process and disturbing ecosystem [60] and [61]. Many queries have to be addressed on their mobility, their environment impact and safety levels, before the technology is commercialized.

\section{Conclusions:}

The small size of nanoparticles together with their high surface to volume ratio can lead to very sensitive detection. These properties will allow in developing miniature, accurate and sensitive pollution monitoring devices. Nanomaterials can also be engineered to actively interact with a pollutant and decompose it in less toxic species. It 
has indeed a huge potential to reduce the overall cost of clean up process of contaminated sites, reduce the contaminants concentration to near zero but proper evaluation at ecosystem level needs to be studied before this technique is used on mass scale. In future nanotechnology holds great promises to be used in detecting and treating the water pollutants on a larger scale.

\section{References:}

[1] M. C. Goode, "Pollution: a global threat," Environment International, vol. 68C, pp. 162-170, 2014.

[2] R.K. Ibrahim, M. Heyyan, M.A. AlSaadi, A. Hayyan., and S. Ibrahim, "Environmental application of nanotechnology: air, soil, water," Environmental Science Pollution Research International, vol. 23, pp.13754-13788, 2016.

[3] N. Ferroudj, J. Nzimoto, A. Davidson, D. Talbot, E. Briot, V. Dupuis, and S. Abramson, " Maghemite nanoparticles and maghemite/silica nanocomposite microspheres as magnetic Fenton catalysts for removal of water pollutants," App. Catal. B: Environment, vol. 136, pp. 9-18, 2013.

[4] X. L. Qu, P.J. Alvarez, and Q.L. Li, "Applications of nanotechnology in water and waste water treatment," Water research, vol. 47, pp. 3931-3946, 2013.

[5] B. Schrick, B.W. Hydutsky, J.L. Blough, and T.E. Mallouk, "Delivery vehicles for zero valent metal nanoparticles in soil and groundwater," Chemistry of materials, vol.16(11), pp. 2187-2193, 2004.

[6] Y. Li, and B. Li, "Study on fungi-bacteria consortium bioremediation of petroleum contaminated mangrove sediments amended with mixed biosurfactants," Advanced materials research, vol.183, pp.1163-1167, 2011.
[7] G. Prokop, G. Schamann, and I. Edelgaard, " Management of contaminated sites in western Europe," European environment agency, Copenhagen Denmark, 2000.

[8] G. Zelmanov, and R. Semiat, "Phenol oxidation kinetics in water solution using iron III-oxide based nano catalysts, Water Research, vol.42, pp. 3848-3856, 2008.

[9] E.C. Catalkaya, U. Bali, and F. Sengul, "Photochemical degradation and mineralization of 4- chlorophenol," Environ. Sci. Poll. Res. Intern., vol.10, pp. 113-120, 2003.

[10] S. Sharma, and A. Bhattacharya, "Drinking water contamination and treatment techniques," Appl. Water Sci., vol. 7, pp. 1043-1067, 2017.

[11] R. Burkhard, A. Deletic, and A.Craig, "Techniques for water and waste water management. A review of techniques and their integration in planning," Urban Water, vol. 2(3), pp.197-221, 2000.

[12] K. Zara, F. Najafi, and H. Sadegh, "Studies of ab initio and Monte Carlo simulation on interaction of fluorouracil anticancer drug with carbon nanotube," J. Nanostructure Chem., vol. 3, pp. 1-8, 2013.

[13] V.K. Gupta, O. Moradi, I. Tyagi, S. Agarwal, H. Sadegh, R. Shahryari Ghoshekandi, A.S.H. Makhlouf, M. Goodarzi, and A. Garshasbi, "Study on the removal of heavy metal ions from industry waste by carbon nanotubes: Effects of the surface modification: a review," Critical Reviews in Environmental Science Technology, vol.46, pp. 93-118, 2016.

[14] G. Krantzberg, A. Tanik, et al., "Book recommendation: Advances in water quality control," Journal of water resources and protection, vol. 02, pp. 995996, 2010. 
[15] S.S. Patil, U.U. Shedbalkar, A. Truskewycz, B.A. Chopade, and A. Ball, "Nanoparticles for environmental clean up: a review of potential risks and emerging solutions," Environmental Technology Innovations, vol. 5, pp. 10-21, 2016.

[16] B. Karn, T. Kuiken, and M. Otto, “ Nanotechnology and in situ remediation: A review of the benefits and potential risks," Environment Health Perspect, vol.117, pp. 1823-1831, 2009.

[17] P. Bardos, B. Bone, P. Daly, D. Elliot, S. Jones, G. Lowry, and C. Merly, “ A risk / benefit appraisal for the Application of nanoscale zero valent iron (nZVI) for the remediation of contaminated sites," WP9 Nanoremediation, 2014.

[18] E. G. Clounon, P. A. Edorh, P. Guedenon, Y. Deguenon, B. Sossou, V.T. Dougnon, F. Loko, and M. Boko, "Risks of drinking water contamination by chemical and organic substances in the lake side city of So Ava in Benin Republic," International Research Journal Environmental Science, vol. 2(1), pp. 49-57, 2013.

[19] M. Hasan, P. Afroza, M. Chowdhury, A. Zaman, M. Hasanuzzaman, M. H. Rakib, and A. Sohel, "Qualitative and quantitative determination of the residual levels of chemical pesticides of the shrimp farms of Bangladesh," International Research Journal Environment Science, vol. 4 (6), pp. 16-27, 2015.

[20] T.E. Cloete, M. Kwaassteniet, M. Botes, and J.M. Lopez Romero, "Nanotechnology in water treatment applications," Book by Caister Academic Press Norfolk, ISBN: 978-1-904455-66-0, 2010.

[21] W . Zhang, " Nanoscale iron particles for environmental remediation: An overview," Journal of nanoparticles research, vol.5, pp. 323-332, 2003.
[22] P.G. Tratnyek, and R.L. Jhonson, "Nanotechnologies for environmental clean up," Nano Today, vol. 1, pp. 44-48, 2006.

[23] G.Q. Lu, and X.S. Zhao, "Nanoporous materials-science and engineering", book published by Imperial college Press, London, 2004.

[24] C.T. Yavuz, "Low field magnetic separation of monodisperse $\mathrm{Fe}_{3} \mathrm{O}_{4}$ nanocrystals," Science, vol. 314, pp. 964967, 2006.

[25] Pen 2015. "The project on emerging nanotechnologies. Nanoremediation map. Available

〈http://www.nanotechproject.org/inventori es/remediation_map/ $\rangle$.

[26] D. Carroll, B. Sleep, M. Krol, H. Boparari, and C. Kocur, "Nanoscale zero valent ion and bimetallic particles for contaminated site remediation," Advances in water research, vol.51, pp. 104-122, 2012.

[27] M. M. Cortalezzi, J. Rose, A. R. Barron, and M. R. Wiesner, "Ceramic membranes derived from ferroxane nanoparticles a new route for the fabrication of iron oxide ultrafiltration membranes", Journal of membrane science, vol. 227, pp. 207-217, 2003.

[28] M.M. Coratelezzi, V. Covin, and R. M. Wiesner, "Controlling submicron particle template morphology: effect of solvent chemistry", Journal of colloid and interface sciences, vol. 283, pp. 366-372, 2005.

[29] N. Hilal, A. Zouhi, H.A. Darwish, A.W. Muhammad, and M.A.A. Arabi, "Comprehensive review of nanofilteration membranes: Treatment, pretreatment, modeling and atomic force microscopy", Desalination, vol.170, pp. 281-308, 2004.

[30] F. D. Guerra, M.F. Attia, D.C. Whitehead, and F. Alexis, "Nanotechnology for environemtal remediation: materials and 
applications," Molecules, vol.1760, pp. 123, 2018.

[31] T. Oyama, A. Aoshima, S. Horikoshi, H. Hidaka, J. Zhao, and N. Serpone, "Solar photocatalysis, photodegradation of a commercial detergent in aqueous titanium oxide dispersions under sunlight radiation", Solar energy, vol. 77, pp. 525532, 2002.

[32] V. Subramanian, E. Wolf, and P.V. Kamat, "Semiconductor metal composite nanostructures. To what extent do metal nanoparticles improve the photocatalytic activity of $\mathrm{TiO}_{2}$ films?", Journal of Physical Chemistry, vol. 105, pp.1143911446, 2001.

[33] C. Jayaseelan, A.A. Rahuman, S.M. Roopan, A.V. Kirthia, K. Kin Se, M. Iyappan, and C. Siva, "Biological approach to synthesize $\mathrm{TiO}_{2}$ nanoparticles using Aeromonas hydrophila and its antibacterial activity," Spectrochimica Acta Part A: Molecular and Biomolecular Spectroscopy, vol. 107, pp. 82-89, 2013.

[34] M.N.Chong, B. Jin, C.W.K. Chow, and C. Saint, "Recent development in photocatalytic water treatment technology: A review," Water Research, vol. 44 (10), pp. 2997-3027, 2010.

[35] M.J. Benotti, B.D. Stanford, E.C. Wert, and S.A. Snyder, "Evaluation of a photocatalytic reactor membrane pilot system for the removal of pharmaceuticals and endocrine disrupting compounds from water," Water research, vol. 43(6), pp.1513-1522, 2009.

[36] P. Westerhoff, H. Moon, D. Minakata, J. Crittenden, "Oxidation of organics in retentates from reverse osmosis wastewater reuse facilities," Water Research, vol. 43(16), pp. 3992-3998, 2009.

[37] J.M.J. Frechet and D.A. Tomalia, "Dendrimers and other dendrites polymers," Book published by Wiley and Sons, ISBN : 9780471638506, New York, 2001.

[38] M.S. Diallo, S. Christie, P. Swaminathan, J.H. Jhonson and W.A. Goddard, "Dendrimer enhanced ultrafilteration. 1. Recovery of $\mathrm{Cu}$ (II) from aqueous solutions PAMAM dendrimers with ethylene diamine core and terminal $\mathrm{NH}_{2}$ groups", Environmental science and Technology, vol. 39, pp. 1366-1377, 2005.

[39] H. Gu, K. Xu, and B. Xu, "Biofunctional magnetic nanoparticles for protein separation and pathogen detection," Chemical communication, vol. 37 (9), pp. 941-949, 2006.

[40] P.K. Rai, V. Kumar, S.S. Lee, N. Raza, K.H. Kim, Y.S. Ok, and D.C.W. Tsang, "Nanoparticle -plant interaction: Implications in energy, environment, and agriculture," Environment International, vol. 119, pp. 1- 19, 2018.

[41] G.I. Rajakumar, A.A. Rahuman, G. Rajakumar, S. Marimuthu, A. Bagavan, C. Jayaseelan, A.A. Zahir, G. Elango, C. Kamaraj, " Synthesis of silver nanoparticles using Nelumbo nucifera leaf extract and its larvicidal activity against malaria and filariasis vectors," Parasitol Res., vol. 108, pp. 693- 702, 2011.

[42] P. Prachi, D. Gautum, D. Madathil, and A.N.B. Nair, "Nanotechnology in waste water treatment: A Review," Intl. J. of Chem. Tech Research, vol. 5, pp.23032308, 2013..

[43] K. Yang, W.H. Wu, Q.F. Jing and L.Z. Zhu, "Aqueous adsorption of aniline, phenol and their substitutes by multiwalled carbon nanotubes," Environmental Science and Technology, vol. 42, pp.7931-7936, 2008.

[44] G.P. Rao, C. Lu, and F.Su, "Sorption of divalent heavy metal ions from aqueous solutions by carbon nanotubes: a review," 
Separation and Purification Technology, vol.58(1), pp. 224-231, 2007.

[45] Y.H. Li, J. Dinga, Z. Luanb, Z. Dia, Y. Zhua, C. Xua, D. Wu, and B. Wei, "Competitive adsorption of $\mathrm{Pb}^{2+}, \mathrm{Cu}^{2+}$ and $\mathrm{Cd}^{2+}$ ions from aqueous solutions by multiwalled carbon nanotubes," Carbon, vol. 41(14), pp. 2787-2792, 2003.

[46] N. Savage, and M.S. Diallo, "Nanomaterials and water purification: Opportunities and challenges," Journal of nanoparticle research, vol. 7(4), pp. 331342, 2005.

[47] S.K. Smart, A.I. Cassidy, G.Q. Lu, and D.J. Martin, " The biocompatibility of carbon nanotubes," Carbon, vol.44 (6), pp. 1034-1047, 2006.

[48] X. Peng, Z. Luan, J. Ding, Z. Di, Y. Li, and B. Tian, "Ceria nanoparticles supported nanotubes for removal of arsenate in water," Mater. Lett., vol. 59, pp. 399-403, 2005.

[49] C.M. Says, J.D. Fortner, W. Guo, D. Lyon, A.M. Boyd, K.D. Ausman, Y.J. Tao, B. Sitharaman, L.J. Wilson, J.B. Hughes, J.L. West, and V.L. Colvin,"The differential cytotoxicity of water soluble Fullerens," Nano Letters, vol. 4(10), pp. 1888-1887, 2004.

[50] A. Bianco, K. Kostarelos, C.D. Partidos, and M. Prato, "Biomedical applications of functionalized carbon nanotubes," Chem. Commun., vol. 1, pp. 571-577, 2008.

[51] J. Jin, R. Li, H. Wang, H. Chen, K. Liang, and J. Ma, "Magnetic Fe nanoparticle functionalized water soluble multiwalled carbon nanotubes towards the preparation of sorbent aromatic compounds removal," The Royal society of chemistry, vol. 4, pp. 386-388, 2007.

[52] C.Lam, J.T. James, R. Mc Cluskey, and R.I. Hunter, "Pulmonary toxicity of carbon nanotubes in Mice 7 and 90 days after intratracheal instillation," Toxicol. Sci., vol. 77, pp. 126-134, 2004.

[53] S. Ramakrishna, K. Fujihara, W.E. Teo, T. Yong, Z. W. Ma, and R. Ramaseshan, " Electrospun nanofibres: solving global issues," Materials today, vol. 9(3), pp. 40-50, 2006.

[54] N. Maximous, G. Nakhla, K. Wong, and W. Wan, "Optimization of $\mathrm{Al}_{2} \mathrm{O}_{3} / \mathrm{PES}$ membranes for waste water fiteration," Separation and purification technology, vol. 73 (2), pp. 294-301, 2010.

[55] G. Bottino, V. Capannelli, V. D'Asti, and P. Piaggio, "Preparation and properties of novel organic inorganic porous membranes," Separation and Purification Technology, vol. 22- 3 (1-3), pp. 269-275, 2001.

[56] M.M. Pendergast, and E.M.V. Hoek, “A review of water treatment membrane nanotechnologies," Energy and environmental Science, vol. 4(6), pp. 1946-1971, 2011.

[57] M.S. Mauter, Y. Wang, K.C. Okemgbo, C.O. Osuji, E.P. Giannelis, and M. Elimelech, "Antifouling ultrafilteration membranes via post fabrication grafting of biocidal nanomaterials," Applied materials and interfaces, vol. 3(8), pp. 2861-2868, 2011.

[58] K. Zodrom, L. Brunet, S. Mahendra, D. Li, A. Zhang, Q.L. Li, and P. J. J. Alvarez, Polysulfone ultrafilteration membranes impregnated with silver nanoparticles show improved biofouling resistance and virus removal," Water research, vol. 43 (3), pp.715-723, 2009.

[59] B. De Gusseme, T. Hennebei, E. Christiaens, H. Savuen, K. Verbeken, J.P. Fitts, N. Boon, and W. Verstraete, "Virus disinfection in water by biogenic silver immobilized in polyvinylidene fluoride membranes," Water research, vol. 45 (4), pp. 1856-1864, 2011. 
[60] N.C. Muller, and B. Nowack, "Exposure modeling of engineered nanoparticles in the environment," Environ. Sci. Technol., vol.42, pp. 4447-4453, 2008.

[61] K.D. Grieger, A. Fjordoge, N.B. Hartmann, E. Eriksson, P.L. Bjerg, and A. Baun, "Environmental benefits and risks of zero valent iron particles (nZVI) for in situ remediation: Risk mitigation or trade off?," J. Contam. Hydrol., vol. 118, pp. 165-183, 2010.

[62] Verma, ASHOK KUMAR, and S. A. D. G. U. R. U. Prakash. "Zooplankton Diversity in Guthia Taal, Wetland of Bahraich (UP), India." International journal of Zoology and Research. 2020b 10.2: 09-18.

[63] Nyssanbayeva, G. R., et al. "Synthesis of modified nanocarbon materials and determination of their adsorption capacity." International Journal of Mechanical and Production Engineering Research and Development 10.1 (2020): 305-314.

[64] Madhusudhan, R., and M. Inayathulla. "Assessment of groundwater quality in and around Bidadi industrial area, Ramanagar district, Karnataka." International Journal of Applied Engineering Research and Development 5.1 (2015): 3-12.

[65] Enwelu, I. A. "Challenges of upscaling water provision among farm households in selected rural communities of Enugu State, Nigeria." International Journal of Agricultural Science and Research (IJASR) 2.4 (2012): 111-120. 